\title{
Application of flow-kinetics model to the PVT growth of SiC crystals
}

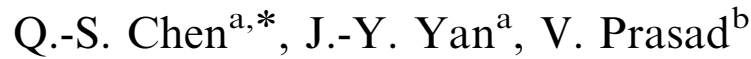 \\ ${ }^{a}$ Institute of Mechanics, Chinese Academy of Sciences, 15 Bei Si Huan Xi Road, Beijing 100080, PR China \\ ${ }^{\mathrm{b}}$ Department of Mechanical and Materials Engineering, Florida International University, $10555 \mathrm{~W}$ Flagler Street, Miami, FL 33174, USA
}

Available online 16 January 2007

\begin{abstract}
A 2-D flow-kinetics model for the PVT growth has been used to describe the phenomena of multi-phase flow, mass transfer and kinetics in the growth process of SiC crystals. The model couples the 2-D gas flow calculations and the growth kinetics at the crystal interface. We calculated the axisymmetric flow field and species concentration field as well as growth rate profile by a finite volume-based code. Species transfer in the cavity is dominated by the diffusion at growth pressures of $8-14 \mathrm{kPa}$. Supersaturation at the crystal interface is less than $1 \mathrm{~Pa}$ at growth pressures of $8-14 \mathrm{kPa}$.
\end{abstract}

(C) 2006 Elsevier B.V. All rights reserved.

PACS: 47.61.Jd; 51.10.+y; 81.10.Aj; 81.10.Bk

Keywords: A1. Fluid flows; A1. Growth models; A2. Growth from vapor; A2. Single-crystal growth; B2. Semiconducting silicon compounds

\section{Introduction}

Wide-bandgap materials such as silicon carbide, aluminum nitride are needed for electronic and optoelectronic applications under high-temperature, high-power and highfrequency conditions. Seeded sublimation growth technique (modified Lely method) has been widely used to produce SiC and AlN crystals since 1970s [1,2]. Many investigators studied the growth process of $\mathrm{SiC}$ crystals by numerical simulation method [3-12]. Hofmann et al. [3,4] developed a numerical process model based on a finite volume scheme FASTEST to simulate the heat transfer in a 2 in $\mathrm{SiC}$ growth set-up, and demonstrated the flow field in the growth chamber caused by the buoyancy effect. Pons et al. $[5,6]$ used a finite element code Flux-Expert to calculate the electromagnetic field and temperature distribution. Selder et al. [7] simulated the heat and mass transfer and compared the calculated growth rates with the experimental data. The 1-D flow-kinetics model for the PVT growth of $\mathrm{SiC}$ was proposed in Refs. [8-10] which assumes that the growth rate is proportional to the supersaturation of $\mathrm{SiC}$ species near the growth interface,

\footnotetext{
*Corresponding author. Tel.: + 861062564199 ; fax: + 861062615524

E-mail address: qschen@imech.ac.cn (Q.-S. Chen).
}

and the transport of $\mathrm{SiC}$ vapor species is by both the Fickian diffusion and Stefan flow. Models of sufficient complexity for the $\mathrm{SiC}$ growth process by different groups were reviewed in Refs. [11,12].

By using the 1-D flow-kinetics model, the growth rate was predicted as a function of the inert gas pressure, the axial temperature gradient and the growth temperature [8], and the predicted growth rates compared well with the experimental growth rate as a function of inert gas pressure measured in Ref. [13]. The relationship between the growth rate and the temperature difference between the charge and the seed was further examined in Ref. [14], and the predicted growth rates using the 1-D flow-kinetics model compared well with the experimental growth rate as a function of temperature difference measured in Ref. [15]. However, for the outward growth of the single crystal using the PVT method, a positive temperature gradient is required along the seed surface. A 2-D flow-kinetics model for the PVT growth is more appropriate to describe the characteristics of the growth process.

The schematic of the PVT growth is shown in Fig. 1, where a sintered $\mathrm{SiC}$ powder charge is placed inside the cylindrical graphite crucible while a seed crystal is attached to the bottom of the crucible lid. An axial temperature gradient in the growth chamber is achieved by properly 


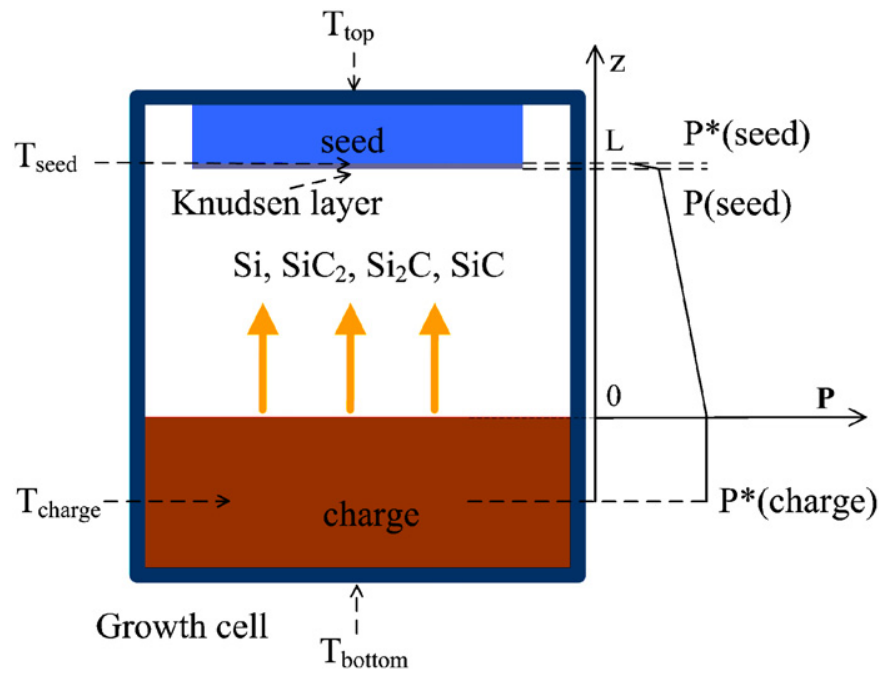

Fig. 1. Physical model of PVT growth of SiC crystals. The coordinate system on the right-hand side gives a sketch of the pressure $P$ along the axial coordinate $z$ in the growth system (details are given in the text).

locating the radio frequency (RF) induction coil; the temperature of the $\mathrm{SiC}$ powder, $T_{\text {charge, }}$ in the lower portion of the crucible is maintained higher than that of the seed crystal, $T_{\text {seed }}$. Temperatures measured outside the crucible, e.g., $T_{\text {top }}$ on the top of the crucible and $T_{\text {bottom }}$ on the bottom of the crucible are used to monitor the growth process. Mass spectrometric investigations conducted in Ref. [16] have shown that the basic components of the evaporation of $\mathrm{SiC}$ are $\mathrm{Si}, \mathrm{SiC}_{2}, \mathrm{Si}_{2} \mathrm{C}$ and $\mathrm{SiC}$. The content of the other components of evaporation $\left(\mathrm{Si}_{2}, \mathrm{C}, \mathrm{C}_{2}, \mathrm{C}_{3}\right)$ in the vapor is insignificant.

\section{Flow-kinetics model for the PVT process}

We here examined the PVT mechanism using the 2-D flow-kinetics model for the multi-phase flow, mass transfer and the growth interface kinetics. We assume that the fluid inside the crucible is Newtonian, the fluid flow is incompressible, and the buoyancy effect is negligible. The Navier-Stokes (N-S) equations for the advection and diffusion are

$\nabla \cdot(\bar{\rho} \mathbf{v})=0$,

$\frac{\partial \bar{\rho} u}{\partial t}+\nabla \cdot(\bar{\rho} u \mathbf{v})=-\frac{\partial p^{\prime}}{\partial z}+\mu \nabla^{2} u$,

$\frac{\partial \bar{\rho} v}{\partial t}+\nabla \cdot(\bar{\rho} v \mathbf{v})=-\frac{\partial p^{\prime}}{\partial r}+\mu \nabla^{2} v-\mu \frac{v}{r^{2}}$,

where $u$ and $v$ are the vertical and radial velocities, respectively, $\mathbf{v}=(u, v), \mu$ is the dynamic viscosity, $p^{\prime}$ is the pressure variation generated by the fluid flow inside the crucible, which is assumed much less than the inert gas pressure. The density $\bar{\rho}$ of gas mixture inside the crucible is given as

$\bar{\rho}=\rho_{\mathrm{SiC}_{2}}+\rho_{\mathrm{Si}}+\rho_{\mathrm{Ar}}=c_{\mathrm{A}} M_{\mathrm{SiC}_{2}}+c_{\mathrm{A}} M_{\mathrm{Si}}+c_{\mathrm{B}} M_{\mathrm{Ar}}$, where the subscripts A and B denote the rate-determining species and inert gas, respectively, $c$ is the molar concentration, and $M$ is the molecular weight. Since the gas mixture can be treated as ideal gas under the growth conditions, the total pressure $p$ of the gas mixture can be expressed as a function of molar concentration of each components using Dalton's law of partial pressures,

$p=2 p_{\mathrm{A}}+p_{\mathrm{B}}=\left(2 c_{\mathrm{A}}+c_{\mathrm{B}}\right) R T$,

where $R$ is the gas constant. Taking into account the advection and Fickian diffusion, the species equation is

$\frac{\partial c_{\mathrm{A}}}{\partial t}+\nabla \cdot\left(c_{\mathrm{A}} \mathbf{v}\right)=D_{\mathrm{AB}} \nabla^{2} c_{\mathrm{A}}$,

where $D_{\mathrm{AB}}$ is binary diffusion coefficient and its dependence on temperature and pressure is given approximately by

$D_{\mathrm{AB}}=D_{0}\left(\frac{T}{T_{0}}\right)^{n}\left(\frac{p_{0}}{p}\right)$,

with $0.05<D_{0}<2 \mathrm{~cm}^{2} \mathrm{~s}^{-1}, n=1.8, T_{0}=273 \mathrm{~K}, p_{0}=1 \mathrm{~atm}$ [8]. Here, we used $D_{0}=0.1 \mathrm{~cm}^{2} \mathrm{~s}^{-1}$ for our simulations.

The relevant reactions on the seed are

$\mathrm{SiC}_{2(\mathrm{~g})}+\mathrm{Si}_{(\mathrm{g})} \Leftrightarrow 2 \mathrm{SiC}_{(\mathrm{s})}$,

$\mathrm{Si}_{2} \mathrm{C}_{(\mathrm{g})} \Leftrightarrow \mathrm{SiC}_{(\mathrm{s})}+\mathrm{Si}_{(\mathrm{g})}$,

where subscripts $s$ and $g$ denote solid and gas, respectively.

The molar flux $J_{\mathrm{A}}$ of the vapor species A,

$J_{\mathrm{A}}=\chi_{\mathrm{A}}\left(p_{\mathrm{A}}(L)-p_{\mathrm{A}}^{*}(L)\right)$,

where $\chi_{\mathrm{A}}=1 / \sqrt{2 \pi M_{\mathrm{A}} R T}$, and $p_{\mathrm{A}}$ and $p_{\mathrm{A}}^{*}$ are the vapor pressure and equilibrium vapor pressure of the transport species, respectively. The rate-determining species, A, is chosen as $\mathrm{SiC}_{2}$ at $T<2900 \mathrm{~K}$, as $\mathrm{Si}$ at $T>2900 \mathrm{~K}$ [17].

If the ratio of reaction rates of Eqs. (8) and (9) is $1: x$, then the ratio of the transport species $\mathrm{SiC}_{2}, \mathrm{Si}$, and $\mathrm{Si}_{2} \mathrm{C}$ are 1: $(1-x): x$. The growth rate $G_{\mathrm{SiC}}$ of $\mathrm{SiC}$ crystal thus becomes

$G_{\mathrm{SiC}}=\frac{(2+x) M_{\mathrm{SiC}}}{\rho_{\mathrm{SiC}}} J_{\mathrm{A}}$.

The calculated equilibrium partial pressures of $\mathrm{SiC}_{2}, \mathrm{Si}$ and $\mathrm{Si}_{2} \mathrm{C}$ at $2600 \mathrm{~K}$ are 100,293 , and $53 \mathrm{~Pa}$, respectively, while the partial pressures at $2700 \mathrm{~K}$ are 310,702 , and $161 \mathrm{~Pa}$. If we set $\mathrm{SiC}_{2}$ as the rate determining species, the ratio of $\mathrm{Si}_{2} \mathrm{C}$ and $\mathrm{SiC}_{2}, x$, is about 0.52 . Since the combined transport rate of $\mathrm{Si}$ and $\mathrm{Si}_{2} \mathrm{C}$ is equal to the transport rate of $\mathrm{SiC}_{2}$, so the value of $x$ does not influence the transport rate of the total species. In the following analysis, we set $x$ as 0 for simplicity. One may multiply the predicted growth rate by a factor of $1+x / 2$ if $x$ is not 0 . The value of $x$ has to be determined by comparison of predictions and experimental measurements.

On the seed, the molar flux of the rate-determining species A can also be expressed in terms of advection and 
a

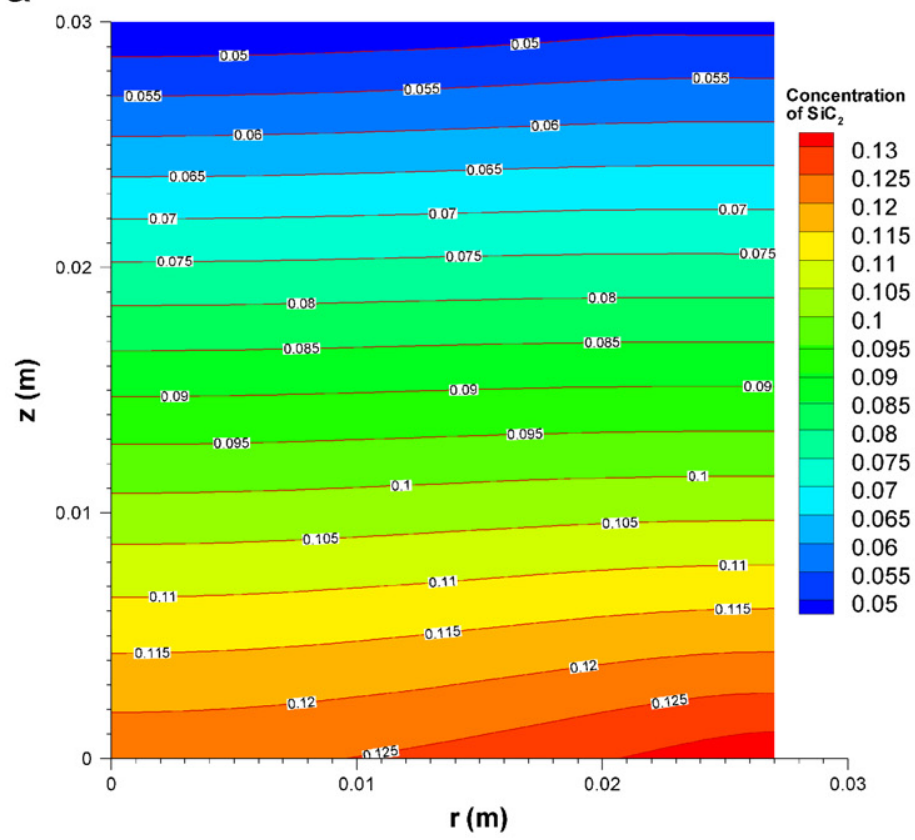

C

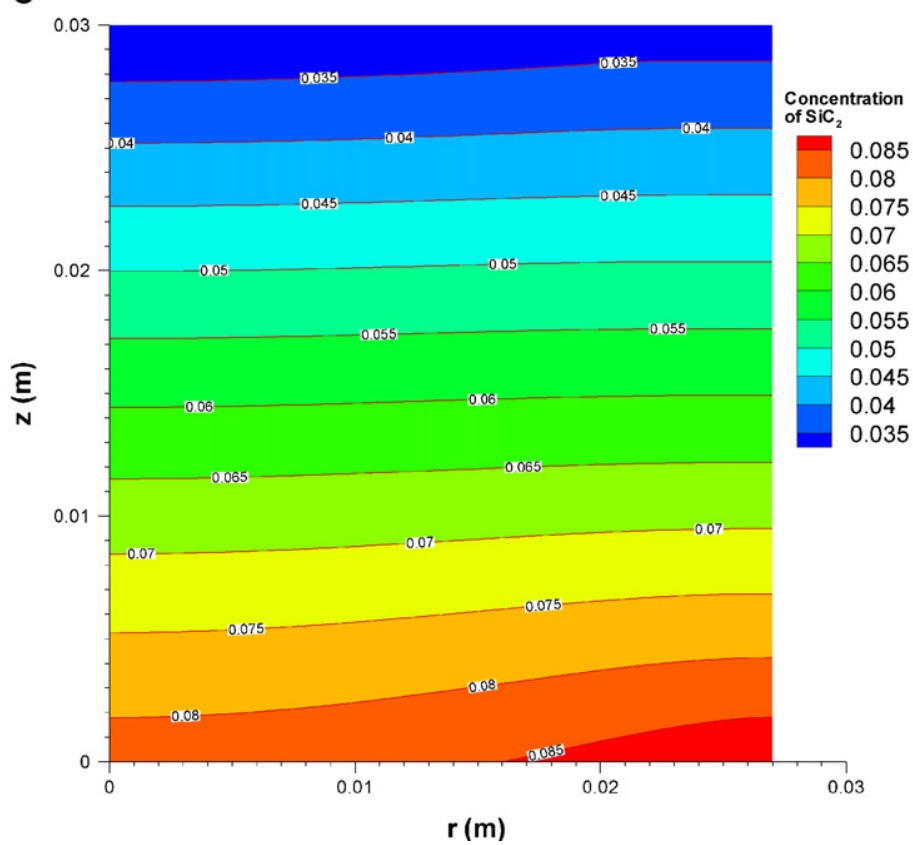

b

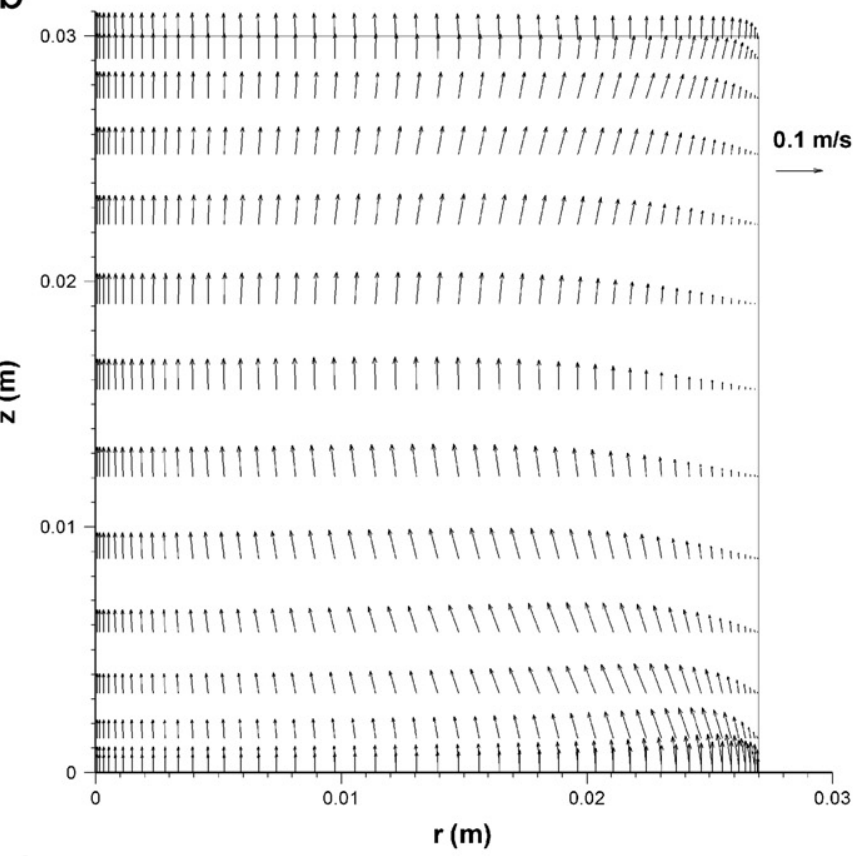

d

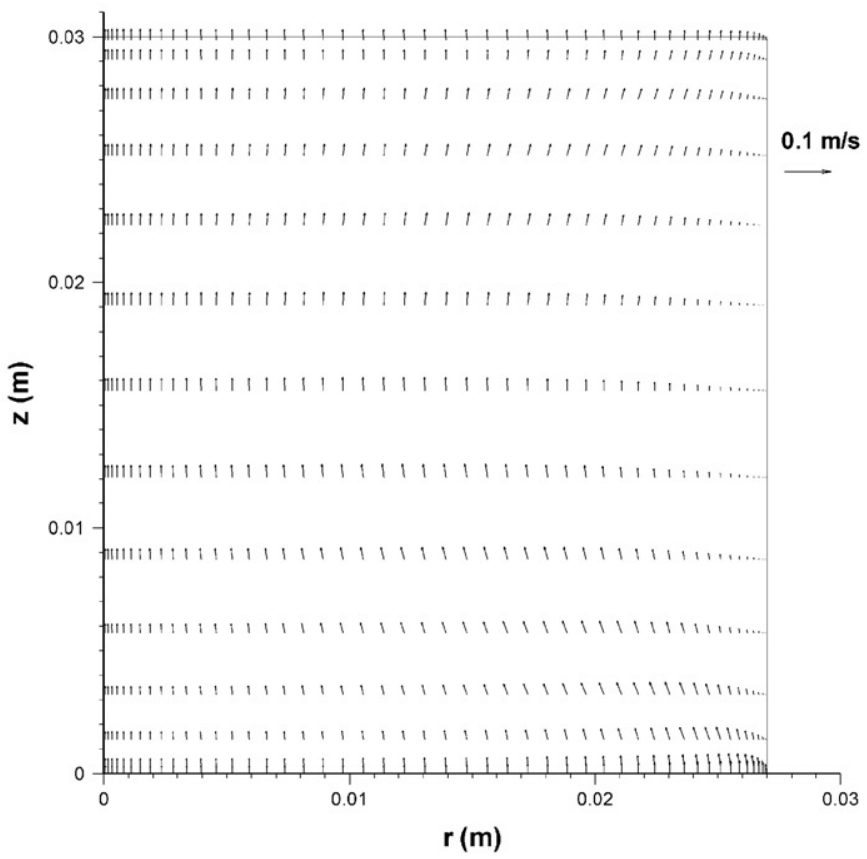

Fig. 2. Concentration distribution (a, c) and flow field (b, d) in the growth chamber at growth pressures of $8 \mathrm{kPa}(\mathrm{a}, \mathrm{b})$, and $12 \mathrm{kPa}(\mathrm{c}, \mathrm{d})$, respectively.

Fickian diffusion,

$J_{\mathrm{A}}=\left.\left(u c_{\mathrm{A}}-D_{\mathrm{AB}} \frac{\partial c_{\mathrm{A}}}{\partial z}\right)\right|_{z=L}$

Accordingly, the molar flux of inert gas B is zero at the seed,

$J_{\mathrm{B}}=\left.\left(u c_{\mathrm{B}}-D_{\mathrm{BA}} \frac{\partial c_{\mathrm{B}}}{\partial z}\right)\right|_{z=L}=0$.
From Eqs. (5), (12) and (13), the molar flux of gas mixture can be written as

$J_{\text {outlet }}=\left.u \frac{p}{R T}\right|_{z=L}=\left.2 \chi_{\mathrm{A}}\left(p_{\mathrm{A}}-p_{\mathrm{A}}^{*}\right)\right|_{z=L}$.

Furthermore, the vapor pressure at the surface of the $\mathrm{SiC}$ source is assumed to be the same as the equilibrium vapor pressure $p^{*}$ corresponding to the maximum temperature in 
the SiC charge,

$\left.p_{\mathrm{A}}\right|_{x=0}=p_{\mathrm{A}}^{*}\left(T_{\text {charge }}\right)$.

The molar flux of inert gas $\mathrm{B}$ is also set as zero at the charge surface,

$J_{\mathrm{B}}=\left.\left(u c_{\mathrm{B}}-D_{\mathrm{BA}} \frac{\partial c_{\mathrm{B}}}{\partial z}\right)\right|_{z=0}=0$.

The equilibrium vapor partial pressure can be obtained by the thermodynamic analysis of the chemical reactions, and is a function of temperature.

We used the iteration method to solve the $\mathrm{N}-\mathrm{S}$ equations and mass equation coupled with the boundary conditions (13)-(16). For example, from Eq. (13) we can obtain velocity, $u$, at the outlet at each time step, and from Eq. (14) we can obtain concentration, $c_{A}$. Then, we solve the $\mathrm{N}-\mathrm{S}$ equations and mass equation by setting the velocity and concentration of species A at the outlet as boundary conditions.

\section{Calculation of the flow and concentration fields}

The temperature field in the growth system was obtained by the thermal analysis considering induction heating and heat transfer [8]. For an induction frequency of $8 \mathrm{kHz}$ and a current of $1400 \mathrm{~A}$ in the induction coil, the seed temperature $T_{\text {seed }}=2671 \mathrm{~K}$, the charge temperature $T_{\text {charge }}=2691 \mathrm{~K}$, and the bottom hole temperature $T_{\text {bottom }}=2540 \mathrm{~K}$. The growth temperature, $T_{\text {seed }}$, may vary for different growth systems and growth pressures, and here we used the current temperature as a case to illuminate the PVT growth mechanism.

The concentration distribution of vapor species $\mathrm{A}\left(\mathrm{SiC}_{2}\right)$ corresponding to the growth pressure of 8 and $12 \mathrm{kPa}$ are presented in Figs. 2a and c, respectively. We can assume the concentration distribution of the combined species $\mathrm{Si}_{2} \mathrm{C}$ and $\mathrm{Si}$ is the same as that of $\mathrm{SiC}_{2}$. There is a large negative concentration gradient along the axial direction from the charge surface to the seed, and the molar fluxes caused by diffusion are around 10.1, 13.0 and 15.7 times as much as that by convection at the center of seed for pressures of 8 , 10 , and $12 \mathrm{kPa}$, respectively. The mass transfer in the growth cavity is dominated by diffusion in the current cases. The concentration at the charge, which remains the highest in the field, is almost two times as much as that of the concentration near the seed. As can be seen from the contour lines, there is a positive concentration gradient on the seed surface, and this is caused by the positive temperature gradient along the seed surface.

The corresponding flow fields are presented in Figs. $2 b$ and $\mathrm{d}$. The velocity profile on the charge surface is not uniform due to the non-uniform temperature distribution, and a high velocity corresponds to a high local temperature. The radial velocity distribution at the seed depends strongly on the growth kinetics, and a high velocity corresponds to a low local temperature. The high velocity induced by a low temperature at the center of seed causes a faster growth rate than that near the edge of the seed leading to a convex shape of the crystal. The velocity on the side wall of the crucible is zero.

The partial pressure at the seed is higher than the local equilibrium vapor pressure so as to maintain a supersaturation required for the growth [8]. However, numerical results show that the supersaturation of $\mathrm{SiC}_{2}$ is less than $1 \mathrm{~Pa}$ at the seed for growth pressures of $8-14 \mathrm{kPa}$ (Fig. 3a) compared to the local equilibrium vapor pressure of more

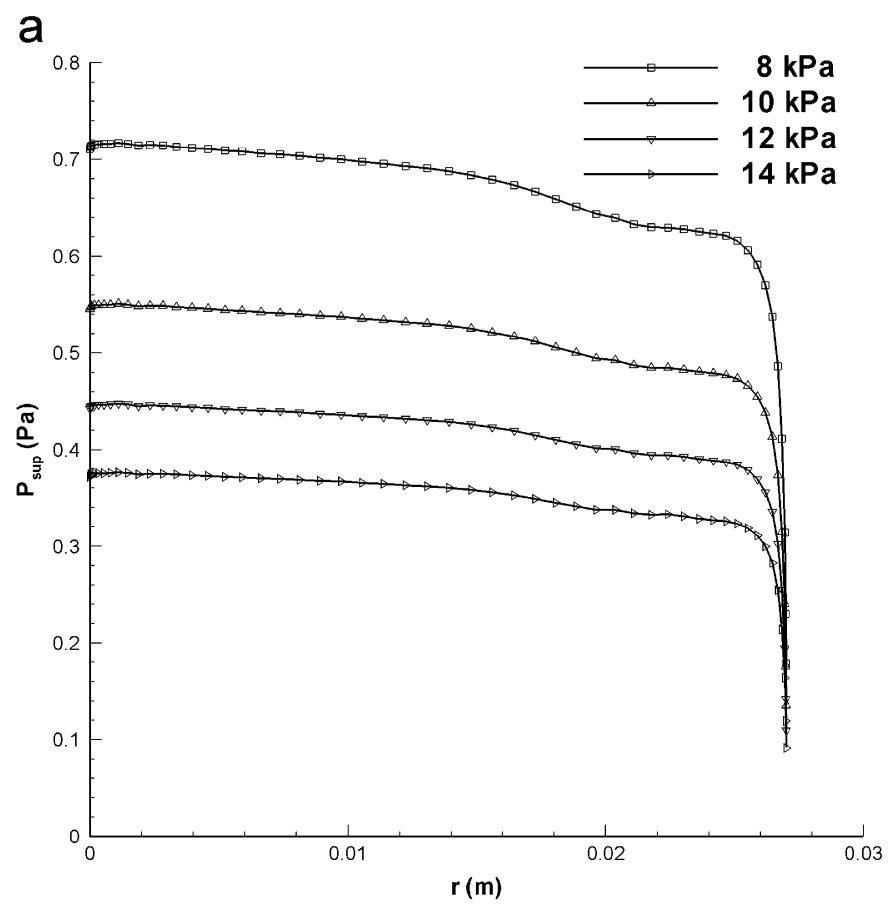

b

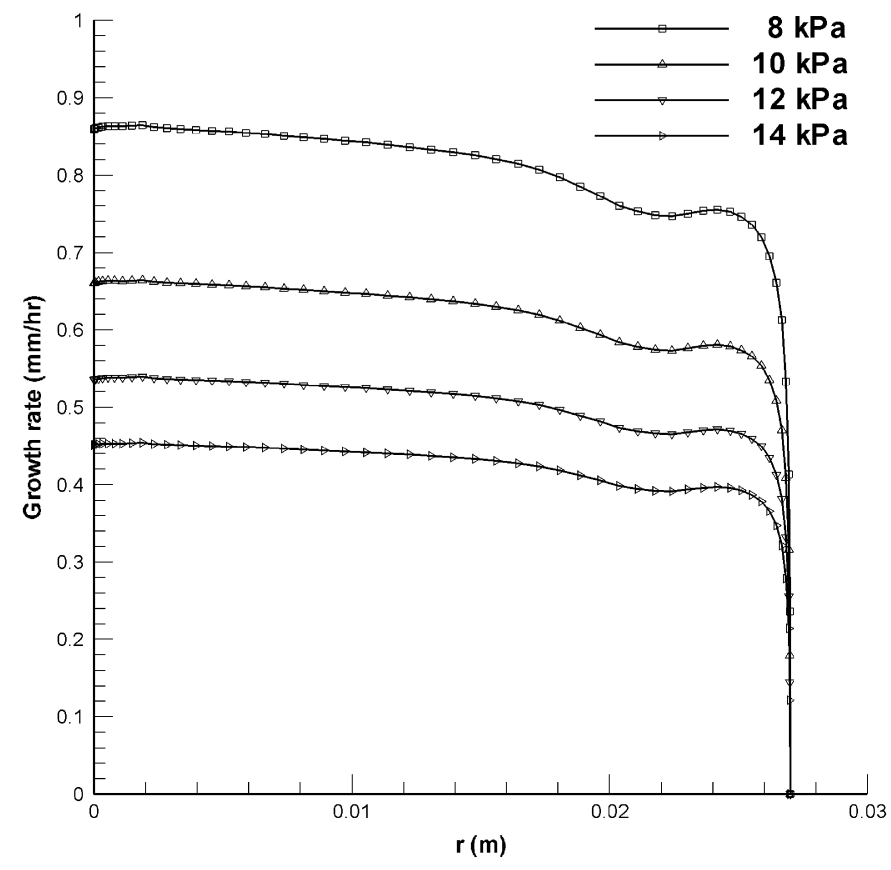

Fig. 3. (a) Supersaturation pressure $p_{\text {sup }}$ and (b) growth rate vs. radial position $r$ at growth pressures of $8,10,12$ and $14 \mathrm{kPa}$. 
than $300 \mathrm{~Pa}$. It shows that only a small supersaturation at the seed is required for the PVT growth. The $\mathrm{SiC}$ species are in non-equilibrium state in the cavity formed between the charge and seed, a high supersaturation in the growth cavity may cause nucleation of small-size $\mathrm{SiC}$ crystals before the deposition on the seed.

Fig. $3 \mathrm{~b}$ shows the predicted growth rate profiles along the seed surface at growth pressures of $8-14 \mathrm{kPa}$. The center of the seed has the highest growth rate ensuring outward growth of $\mathrm{SiC}$ crystal. The growth rate decreases from the center of seed to the crucible wall allowing growth of the single crystal. Growth rate then increases near the crucible wall causing polycrystalline growth there. The predicted growth rates agree well with the measured growth rates in our lab, and more experimental results will be obtained in the future.

\section{Conclusions}

A flow-kinetics model for the PVT growth has been developed. The model couples the 2-D gas flow calculations and the growth kinetics at the crystal interface. The supersaturaton theory is used at the interface, which assumes that the growth rate is proportional to the supersaturation of a rate-determining species. The transport of $\mathrm{SiC}$ vapor species by the diffusion and the Stefan flow in the growth cavity was analyzed. Species transfer in the cavity is dominated by diffusion at growth pressures of $8-14 \mathrm{kPa}$. Supersaturation at the crystal interface is less than $1 \mathrm{~Pa}$ at growth pressures of $8-14 \mathrm{kPa}$.

\section{Acknowledgments}

This work was supported by the National Science Foundation of China (10472126, 10432060) and the Knowledge Innovation Program of Chinese Academy of Sciences.

\section{References}

[1] Yu.M. Tairov, V.F. Tsvetkov, J. Crystal Growth 43 (1978) 209.

[2] G.A. Slack, T.F. McNelly, J. Crystal Growth 34 (1976) 263.

[3] D. Hofmann, M. Heinze, A. Winnacker, F. Durst, L. Kadinski, P. Kaufmann, Y. Makarov, M. Schäfer, J. Crystal Growth 146 (1995) 214.

[4] D. Hofmann, R. Eckstein, M. Kölbl, Y. Makarov, St.G. Müller, E. Schmitt, A. Winnacker, R. Rupp, R. Stein, J. Völkl, J. Crystal Growth 174 (1997) 669.

[5] M. Pons, E. Blanquet, J.M. Dedulle, I. Garcon, R. Madar, C. Bernard, J. Electrochem. Soc. 143 (1996) 3727.

[6] M. Pons, M. Anikin, K. Chourou, J.M. Dedulle, R. Madar, E. Blanquet, A. Pisch, C. Bernard, P. Grosse, C. Faure, G. Basset, Y. Grange, Mater. Sci. Eng. B 61-62 (1999) 18.

[7] M. Selder, L. Kadinski, F. Durst, T. Straubinger, D. Hofmann, P. Wellmann, Mater. Sci. Forum 338-342 (2000) 31.

[8] Q.-S. Chen, H. Zhang, V. Prasad, C.M. Balkas, N.K. Yushin, S. Wang, J. Crystal Growth 224 (1-2) (2001) 101.

[9] Q.-S. Chen, R.-H. Ma, H. Zhang, V. Prasad, C.M. Balkas, N.K. Yushin, J. Crystal Growth 225 (2-4) (2001) 299.

[10] V. Prasad, Q.-S. Chen, H. Zhang, J. Crystal Growth 229 (1-4) (2001) 510.

[11] Q.-S. Chen, V. Prasad, H. Zhang, M. Dudley, Silicon carbide crystals - Part II: process physics and modeling, in: K. Byrappa, T. Ohachi (Eds.), Crystal Growth Technology, Springer, William Andrew, NY, 2003, p. 233.

[12] M. Pons, R. Madar, T. Billon, Principles and limitations of numerical simulation of SiC Boule growth by sublimation, in: W.J. Choyke, H. Matsunami, G. Pensl (Eds.), Silicon Carbide Recent Major Advances, Springer, New York, 2004, p. 121.

[13] G. Augustine, H.McD. Hobgood, V. Balakrishna, G. Dunne, R.H. Hopkins, Phys. Stat. Sol. B 202 (1997) 137.

[14] Q.-S. Chen, H. Zhang, V. Prasad, C.M. Balkas, N.K. Yushin, J. Heat Transfer 123 (2001) 1098.

[15] C.M. Balkas, A.A. Maltsev, M.D. Roth, N.K. Yushin, Mater. Sci. Forum 338-342 (2000) 79.

[16] J. Drowart, G. De Maria, in: J.R. O’Connor, J. Smiltens (Eds.), Silicon Carbide, Pergamon Press, Oxford, 1960, p. 16.

[17] S.K. Lilov, Mater. Sci. Eng. B 21 (1993) 65. 